\title{
LONG-TERM CYCLING OF CARBON-BASED SUPERCAPACITORS IN AQUEOUS
}

\section{MEDIA}

\author{
V. Ruiz, R. Santamaría, M. Granda and C. Blanco* \\ Instituto Nacional del Carbón, CSIC, Apdo. 73, 33080-Oviedo, Spain
}

\begin{abstract}
.-
The behaviour of mesophase-derived electrodes on long-duration cycling conditions was studied in $1 \mathrm{M}$ sulfuric acid and $6 \mathrm{M}$ potassium hydroxide. Variation in the specific capacitance values with the number of cycles shows a good cycling life performance in acidic media but very poor in an alkaline electrolyte. The total loss of capacitance after 7,000 cycles in acidic media is $8 \%$ at $0.6 \mathrm{~V}$ and $16 \%$ at $1 \mathrm{~V}$, whereas in the basic electrolyte the reduction in the capacitance values is $72 \%$, even at a very small operating voltage $(0.6 \mathrm{~V})$. This behaviour was associated to the strong oxidation of the positive electrode caused by the progressive shift of the working potential towards very positive potential values during cycling.
\end{abstract}

Key words: Activated carbon, electrochemical capacitor, double layer, pseudocapacitance, long-term cycling

*Corresponding author: clara@incar.csic.es; Tlf: +34 985119090; Fax.: + 34985297662 


\section{1.- INTRODUCTION}

Electrochemical double layer capacitors (EDLC's) are energy storage devices with a wide range of applications related to their fast energy delivery (e.g. telecommunications systems, maintenance-free traffic lights, uninterruptible power sources, and hybrid electric vehicles among others) [1]. The storage of energy in electrochemical capacitors can arise from either electrostatic charging or from pseudocapacitative chage-discharge [2]. In the first case, electrolyte ions are accumulated at the electrode/electrolyte interface forming the socalled double layer in a similar way as in conventional capacitors. By utilizing high surface area electrodes the amount of charge stored, and consequently the capacitance of the device, is several orders of magnitude higher than that of conventional electrolytic capacitors. In the second case, pseudocapacitance arises from faradaic processes of electroactive species, such as polymeric materials [3], metal oxides [4,5] and certain functionalities at the surface of carbon materials $[6,7,8]$.

It is generally believed that pseudocapacitance in carbon materials is largely based on the redox reactions of surface quinoid functionalities, whose reduction requires protons to proceed $[9,10]$. Nevertheless, some other oxygenated functional groups might be electrochemically active at the working potentials of the acidic solutions, such as some pyrone groups [11,6]. Therefore, and as may be expected, faradic phenomena have a large dependence on the $\mathrm{pH}$ of the solution. In this sense, enormous differences in capacitance values can be found depending on the electrolyte used. For carbon materials in neutral solutions, specific capacitance values between $8-12 \mu \mathrm{F} \mathrm{cm}^{-2}$ have been reported and between $15-20 \mu \mathrm{F} \mathrm{cm}^{-2}$ in the case of acidic media [12]. Despite that its study is not so frequent, redox reactions in basic media are also possible [13]. 
As a general trend, for the same active electrode material, higher capacitance values are found in acidic media compared to those obtained in basic media. Despite that this tendency is followed by the majority of the materials [14,7], a few examples can be found following the opposite trend. Rojo et.al. [15] reported capacitance values for activated carbon nanofibers of about $60 \mathrm{~F} \mathrm{~g}^{-1}$ when $6 \mathrm{M} \mathrm{KOH}$ was used as electrolyte and of around $40 \mathrm{~F} \mathrm{~g}^{-1}$ when using $2 \mathrm{M} \mathrm{H}_{2} \mathrm{SO}_{4}$. This difference was attributed by the authors to the larger sizes of the hydrated $\mathrm{H}_{3} \mathrm{O}^{+}$and $\mathrm{HSO}_{4}{ }^{-}$ions compared to the hydrated $\mathrm{K}^{+}$and $\mathrm{OH}^{-}$ions $[16,17]$. However, the different redox activity in each media seems to be a more plausible explanation, as the average pore size of the active material is large enough to allow the access of the ions compared. The work carried out by Pietrzak et al. [18] reported that samples containing significant amounts of nitrogen showed higher capacitance values in alkaline media than in acidic media due to the presence of pseudofaradaic reactions of the nitrogen functional groups.

In general terms, the presence of the so-called pseudocapacitance has been related in literature to poor cycle life [19] contrary to what occurs in organic media, where only purely charge separation occurs and good cycling stability is typically reported [20]. Investigations in this field are rarely reported, despite that the cyclability of supercapacitors is a property of mayor importance. The present work investigates the effect of the electrolyte (basic or acidic) in the long-term stability of carbon-based supercapacitors. 


\section{2.- EXPERIMENTAL}

\section{1.- Active material.-}

The activated carbon M-AC was obtained by chemical activation of a mesophasederived pitch (AR24) using potassium hydroxide in a proportion of 3:1 (KOH:AR24). The activation procedure has been previously described [21]. Physical adsorption of nitrogen at $77 \mathrm{~K}$ was carried out in order to characterize the porous texture of the activated carbon and carbon-based electrodes. Isotherms were performed in an ASAP 2020 Micromeritics volumetric system using around $50 \mathrm{mg}$ of sample for each measurement. The apparent specific surface area was determined from the $\mathrm{N}_{2}$-adsorption isotherm using the BET equation. The total micropore volume $\left(\mathrm{V}_{\mathrm{N} 2}\right)$ was calculated by applying the DubininRadushkevich (DR) equation to the $\mathrm{N}_{2}$-adsorption isotherms [22]. The microporous surface area was obtained from the equation: $\mathrm{S}_{\mathrm{mic}}\left(\mathrm{m}^{2} \mathrm{~g}^{-1}\right)=2000 \mathrm{~V}_{\mathrm{N} 2}\left(\mathrm{~cm}^{3} \mathrm{~g}^{-1}\right) / \mathrm{L}_{0}(\mathrm{~nm})$, where $\mathrm{L}_{0}$ represents the average micropore width [23].

The electro-oxidation of the activated carbon M-AC was carried out in a conventional three-electrode system. Around $100 \mathrm{mg}$ of material was subjected to $+0.4 \mathrm{~V}$ vs. NHE in a $\mathrm{N}_{2}$ bubbling solution of $6 \mathrm{M} \mathrm{KOH}$. Then the sample was washed using distilled water and dried in a vacuum oven at $110^{\circ} \mathrm{C}$ overnight. The resultant material was labelled EO-M-AC+0.4. The amount of oxygen functional groups in the sample was evaluated by means of temperatureprogrammed desorption (TPD). About $150 \mathrm{mg}$ of sample was placed in a U-shaped quartz cell and heat treated to $1000{ }^{\circ} \mathrm{C}$ at an increasing temperature of $10^{\circ} \mathrm{C} \mathrm{min}{ }^{-1}$. On-line mass spectrometry was used to measure the decomposition products $\left(\mathrm{CO}\right.$ and $\left.\mathrm{CO}_{2}\right)$. 
The oxygen content of the activated carbons was directly determined using a LECOTF-900 furnace coupled to a LECO-CHNS-932 microanalyzer.

\section{2.-Electrode preparation and electrochemical measurements.-}

Disk type electrodes of $12 \mathrm{~mm}$ in diameter were prepared using $10 \mathrm{wt} \%$ of polyvinylidene fluoride (PVDF) as binder and $90 \mathrm{wt} \%$ of active material. The electrodes were dried overnight before the cell assembly. Gold disks were used as current collectors and glassy fiber disks as separators.

The electrochemical tests were performed in PFA (polyfluoroalkoxy) "T"-type Swagelok $^{\circledR}$ cells In this configuration a two-electrode cell is assembled and in the third end connection a reference electrode is incorporated. This configuration allows the potential at which anode and cathode are operating to be determined, as these can be monitored throughout the two-electrode experiments. The reference electrodes used were $\mathrm{Hg} / \mathrm{Hg} \mathrm{SO}_{4}$ or $\mathrm{Hg} / \mathrm{HgO}$ depending on the electrolytic media used, where one of the carbon electrodes acted as counter electrode. Aqueous solutions of $1 \mathrm{M}$ sulfuric acid, $6 \mathrm{M}$ potassium hydroxide and $1 \mathrm{M}$ $\mathrm{LiCl}$ where used as electrolytes.

The electrochemical measurements were conducted in a Biologic multichannel potenciostat. Galvanostatic cycling at a current load of $500 \mathrm{~mA} \mathrm{~g}^{-1}$ was performed for the long-term cycling experiments at two different operating voltages: 0.6 and $1 \mathrm{~V}$. The capacitance of the system was obtained applying the equation: $\mathrm{C}_{\text {cell }}(\mathrm{F})=\mathrm{I} /\left(\mathrm{dV} \mathrm{dt}^{-1}\right)$ to the galvanostatic cycles performed at constant current, I, (avoiding the ohmic drop). The specific capacitance values for the electrode, $\mathrm{C}\left(\mathrm{F} \mathrm{g}^{-1}\right)$, was obtained from the following expression: 
$\mathrm{C}=2 \mathrm{C}_{\text {cell }} / m$, where $m$ is the mass of active material in the lightest electrode. Cyclic voltammetry was also carried at a scan rate of $1 \mathrm{mV} \mathrm{s}^{-1}$. Impedance spectroscopy analyses were conducted at $0 \mathrm{~V}$, in the completely discharged state, varying frequencies between $1 \mathrm{mHz}-100 \mathrm{kHz}$ with an amplitude of $\pm 10 \mathrm{mV}$.

\section{3.- RESULTS AND DISCUSSION}

The textural and chemical properties of the active material used in the present study (M-AC) have been described elsewhere [7]. M-AC is mainly a microporous material, with a microporous surface area of $1531 \mathrm{~m}^{2} \mathrm{~g}^{-1}$ and an apparent BET area of $2000 \mathrm{~m}^{2} \mathrm{~g}^{-1}$. Regarding its chemical properties, M-AC has a significant amount of oxygenated functionalities (3.5 wt. \% obtained by elemental analysis).

Figure 1 shows the specific capacitance values at increasing current densities obtained for $\mathrm{M}-\mathrm{AC}$ in three aqueous electrolytes: $1 \mathrm{M} \mathrm{H}_{2} \mathrm{SO}_{4}, 6 \mathrm{M} \mathrm{KOH}$ and $1 \mathrm{M} \mathrm{LiCl}$. At the lowest current density measured $\left(0.88 \mathrm{~mA} \mathrm{~cm}^{-2} / 40 \mathrm{~mA} \mathrm{~g}^{-1}\right)$ the specific capacitance values obtained were: 242, 208 and $145 \mathrm{~F} \mathrm{~g}^{-1}$ for $\mathrm{H}_{2} \mathrm{SO}_{4}, \mathrm{KOH}$ and $\mathrm{LiCl}$, respectively. These differences in capacitance might arise either from the different accessibility of the ions into the porous network or from the dissimilar chemical reactions occurring onto the carbon surface. M-AC has an average pore size of $0.97 \mathrm{~nm}$ as described in ref. [7]. In addition to this, the ions used in this study have stokes radius [24] lower than $0.24 \mathrm{~nm}$ (radius of the solvated species). Thus, the problems of accessibility of the ions can not be taken into account as demonstrated elsewhere for aqueous solutions $[25,26]$. In the absence of any faradic processes, capacitance values should be similar for the three electrolytes. Therefore, differences found in the electrochemical behaviour of M-AC can only be assigned to its different faradic contribution 
in each electrolyte. Based on these results, acidic media is expected to favour a higher contribution of pseudocapacitance, followed by the basic, followed by the neutral electrolyte. This circumstance has been explained in the literature based on the activity of the quinone/hydroquinone couple in the presence of protons [10]. The presence of pseudocapacitance in $\mathrm{KOH}$ has not been studied in such detail as those occurring in acidic media. Nonetheless, some studies, as those carried out by Andreas et al. [10] report a $40 \%$ loss of capacitance when varying the $\mathrm{pH}$ of the electrolyte from 14 to 5 .

Capacitance values for $\mathrm{LiCl}$ appear to be very dependent on the current load. This indicates diffusion issues of the ions due to its lower ionic conductivity. For this reason, the long-term experiments were not conducted in this electrolyte.

The presence of pseudocapacitance in acidic and basic media is also evidenced from the cyclic voltamograms obtained in a three-electrode configuration (Figure $2 \mathrm{a}$ and $2 \mathrm{~b}$ ). The voltage window in which the positive and negative electrode are operating in a two-electrode configuration are also incorporated on top of the X-axis. For both electrolytes, a clear deviation of the ideal rectangular shape is observed. In the acidic media (Figure $2 \mathrm{a}$ ), the $\mathrm{CV}$ response exhibits a set of anodic and cathodic peaks which are pseudocapacitive in nature attributable to the oxidation/reduction of some surface functionalities on the carbon [7]. The redox reactions occur both in the anodic and cathodic regions, which means that this pseudocapacitance is readily used in a symmetric cell. However, in the case of the alkaline medium the redox reaction of surface groups shifts to negative potentials (Figure $2 b$ ). As previously reported [7], the poorest performance of the positive electrode in basic media limits the capacitance of the whole device in the two-electrode configuration. This explains why the capacitance values in sulfuric acid are higher than in potassium hydroxide. 
The large contribution of pseudocapacitance both in acidic and basic media, deduced from Figures 1 and 2, is expected to negatively affect the long-term behaviour of the supercapacitors [19]. The variation in the specific capacitance values of M-AC during cycling is represented in Figure 3 and the specific capacitance values obtained for the first and last cycles are summarised in Table 1. The capacitance values in sulfuric acid are rather stable, with a reduction of only $8 \%$ after 7,000 cycles at $0.6 \mathrm{~V}$, and $16 \%$ at $1 \mathrm{~V}$. As expected, the reduction is higher at higher voltage window, as the participation of faradaic currents (e.g. redox reactions, aqueous-solution decomposition, moderate carbon oxidation $[1,27,28])$ that incorporate irreversibility into the electrochemical cell is more evident. On the contrary, the long-term cycling in basic media, even at $0.6 \mathrm{~V}$, was rather poor with a reduction in the capacitance values of $72 \%$ after 7,000 cycles. This reduction is dramatic after 6,000 cycles.

The poor electrochemical behaviour of $\mathrm{M}-\mathrm{AC}$ in $\mathrm{KOH}$ after 7,000 cycles is clearly evidenced by the distortion of the shape of the cyclic voltammograms and galvanostatic charge-discharge curves (Figure $4 \mathrm{a}$ and $\mathrm{b}$, respectively). At the initial stages of cycling, $\mathrm{CV}$ and charge-discharge profiles show the typical behaviour of EDLC's. However, after several cycles, this behaviour is distorted.

These results suggest that the testing of active materials during a significant period of time is of vital importance in order to evaluate their suitability to actuate in real operation conditions.

For a deeper understanding of the changes occurring in the cell, impedance spectroscopy measurements were carried out. Figure 4c represents the Nyquist plot obtained 
after the first, $6,000^{\text {th }}$ and $7,000^{\text {th }}$ cycles and Figure $4 \mathrm{~d}$ shows the amplitude of each spectrum in the high-frequency region. The increase in the diameter of the semicircle in the mediumhigh range of frequencies indicates a worsening in the intrinsic resistance of the active material. At low frequencies, the impedance should be a vertical line parallel to the imaginary axis, which corresponds to the capacitive behaviour of the material. However, there is a great deviation form the theoretical performance that becomes particularly noticeable after 7,000 cycles. The same type of experiments performed in acidic media show a much lower variation in the electrochemical behaviour with cycling (Figure 4e). Although some alteration on the impedance spectra are expected [29,30], the great modification observed in $\mathrm{KOH}$ clearly indicates the degradation of the electrochemical system.

In order to achieve a better understanding of the different extent of degradation observed in the different media, the variation in the voltages at which the positive and negative electrodes are operating was monitored during the long-term experiments. Figure 5a shows a charge-discharge cycle obtained in sulfuric acid (cell voltage, right Y-axis) and the voltage profile where anode and cathode are operating (left Y-axis). When the cell is in the completely discharged state $(0 \mathrm{~V}$, right $\mathrm{Y}$-axis $)$ anode and cathode stand at the same potential $(+0.48 \mathrm{~V}$ vs NHE), that may be defined as equilibrium potential or rest potential (which is characteristic of the active material and media used). When the supercapacitor is in the completely charged state $(0.6 \mathrm{~V})$ the positive electrode reaches $+0.77 \mathrm{~V}$ vs NHE, whereas the negative electrode decreases to $+0.18 \mathrm{~V}$ vs NHE. Thus, the overall cell voltage $(0.6 \mathrm{~V})$ is evenly distributed between anode and cathode $(0.3 \mathrm{~V}$ each electrode) (see summary in Table 2), splitting the total range of voltage into two equal parts. It was found that these values did not change during cycling. On the contrary, in basic media the operating potential of each electrode vary visibly after the long-term cycling experiments towards more positive 
values (Figure 5b). Additionally, the positive electrode increases very importantly its operating voltage $(\Delta \mathrm{V})$, from 0.35 in the first cycle, to $0.5 \mathrm{~V}$ after 7,000 cycles, while in the negative electrode this is reduced from 0.22 to only $0.07 \mathrm{~V}$. This indicates that the capacitance of the positive electrode is decreasing with cycling. Considering the shift of this electrode to very positive potentials, it is reasonable to assign its degradation to irreversible oxidation of the active material, which is agreement with other authors $[13,31]$.

With the aim of studying the alterations suffered by M-AC upon cycling, the activated carbon was subjected to $+0.4 \mathrm{~V}$ vs. NHE to simulate the processes occurring in the positive electrode in a two-electrode cell after subjected to long-cycling experiments. The oxygen content determined by direct elemental analysis increased drastically, from 3.5 wt. $\%$ in the starting material up to 15 wt. \% in EO-M-AC+0.4. Figure 6 shows the curves corresponding to $\mathrm{CO}$ and $\mathrm{CO}_{2}$ evolution for the activated carbon (M-AC) and for the resultant electrooxidized sample (EO-M-AC+0.4). The amount of CO-evolving groups does not change substantially, whereas the groups responsible for the $\mathrm{CO}_{2}$ evolution significantly increased (from 0.2 to $0.8 \mathrm{mmol} / \mathrm{g}$ ). When moderate oxidation takes place, the morphology of the carbon material does not change significantly, although some oxygen functional groups can be created at the surface of the material (i.e., hydroxyl groups) that could lead to an improvement in wettability [32] and/or could lead to enhanced specific capacitance values [33]. However, a strong oxidation can lead to deeper structural modifications that can cause the degradation of the carbon material (i.e. carboxy groups) [34], producing carbon corrosion products $\left(\mathrm{CO}\right.$ and $\left.\mathrm{CO}_{2}\right)$ together with oxygen [35,36]. Additionally, the evolution of $\mathrm{CO}_{2}$ in basic media produces carbonate ions $\left(\mathrm{CO}_{3}{ }^{2-}\right)$ obstructing and retarding the ions mobility in porous materials [31]. 
On the view of these results, the huge decrease in capacitance values observed in $\mathrm{KOH}$ (especially after 6,000 cycles) can be attributed to the oxidation of the positive electrode, which becomes drastic after over passing a given potential.

\section{4.- CONCLUSIONS}

AC-M demonstrated an extremely poor long-term cycling performance in $\mathrm{KOH}$, especially after 6,000 cycles, even at a low operating voltage window, $0.6 \mathrm{~V}$. This behaviour was associated to the strong oxidation of the positive electrode caused by the progressive shift of the working potential towards very positive potentials during cycling.

On the contrary, the performance of AC-M during long-term cycling in sulfuric acid was good, with a reduction of specific capacitance values of only $8 \%$ after 7,000 galvanostatic cycles at $0.6 \mathrm{~V}$ and $16 \%$ at $1 \mathrm{~V}$, despite the high contribution of pseudocapacitance present in this media. In this electrolyte no change of the working potentials of each electrode has been observed.

Acknowledgements.- This work has been performed with financial support from MEC (project MAT2007-61467) and FICYT (project IB05-086-C1). V. Ruiz acknowledges a predoctoral research grant from FICYT. 


\section{REFERENCES}

[1] R.Kötz and M. Carlem, Electrochim. Acta 45 (2000) 2483.

[2] B. E. Conway, Electrochemical Supercapacitors, Scientific Fundamentals and Technological Applications, Kluwer Academics/Plenum New York, 1999.

[3[ C. Peng, S. Zhang, D. Jewell, G. Chen, Prog. Nat. Sci. 18, issue 7 (2008) 777.

[4] C-C Hu, Y.H. Huang, K-H Chang, J. Power Sources 108 (2002) 117.

[5] K.W. Nam, K.B. Kim, J. Electrochem. Soc. 149 (2002) A346.

[6] M. Seredych, D. Hulicova-Jurcakova, G.Q. Lub, T.J. Bandosz, Carbon 46 (2008) 1475

[7] V. Ruiz, C. Blanco, E. Raymundo-Piñero, V. Khomenko, F. Béguin, R. Santamaría, Electrochim. Acta 52 (2007) 4969.

[8] G. Lota, K. Lota, E. Frackowiak, Electrochem. Commun. 9, Issue 7 (2007) 1828.

[9] C.A. León y León, L.R. Radovic. Interfacial Chemistry and Electrochemistry of Carbon Surfaces. In Chemistry and Physics of Carbon; P. A. Thrower, Ed.; Marcel Dekker: New York, 1994; Vol. 24, p 213

[10] H. A. Andreas, B. E. Conway, Electrochim. Acta 51 (2006) 6510.

[11] E. Fuente, J.A. Menéndez, D. Suárez, M.A. Montes-Morán, Langmuir 19 (2003) 3505.

[12] A. Soffer, M. Folman, J. Electroanal. Chem. 38 (1972) 25.

[13] M. Zuleta, P. Björnbom, A. Lundblad, J. Electrochem. Soc. 153 (2006) A48.

[14] K. Jurewicz, C. Vix-Guterl, E. Frackowiak, S. Saadallah, M. Reda, J. Parmentier, J. Patarin, F. Béguin, J. Phys. Chem. Solids 65 (2004) 287.

[15] C. Merino, P. Soto, E. Vilaplana-Ortego, J. M. Gómez de Salazar, F. Pico, J. M. Rojo, Carbon 43 (2005) 551.

[16] D. Qu, H. Shi, J. Power Sources 74 (1998) 99.

[17] M. Endo, T. Takeda, Y. J. Kim, K. Koshiba K. Ishii, Carbon Sci. 1 (2001) 117.

[18] R. Pietrzak, K. Jurewicz, P. Nowicki, K. Babeł, H. Wachowska, Fuel 86 (2007) 1086. 
[19] K. Kierzek, E. Frackowiak, G. Lota, G. Gryglewicz, J. Machnikowski Electrochim. Acta $49(2004) 515$.

[20] C. Portet, P.L. Taberna, P. Simon, E. Flahaut, C. Laberty-Robert, Electrochim. Acta 50 (2005) 4174 .

[21] E. Mora, V. Ruiz, R. Santamaría, C. Blanco, M. Granda, R. Menéndez, J.M. JuárezGalán, F. Rodríguez-Reinoso, J. Power Sources 156 (2006) 719.

[22] M. M. Dubinin, D. A Cadenhead (Ed.), "Progress in Surface and Membrane Science", Vol. 9, Academic Press, London, 1975.

[23] H. F. Stoeckli, en J. W. Patrick (Ed.), "Porosity in carbons”, Edward Arnold, London, Ch.3, 1995.

[24] R.H. Stokes, R.A. Robinson. "The Stokes and Robinson hydration theory: A modification with application to concentrated electrolyte solutions”. Eds. Springer Netherlands. Vol. 11, 1982.

[25] G. Salitra, A. Soffer, L. Eliad, Y. Cohen, D. Aurbach, J. Electrochem. Soc. 147, Issue 7 (2000) 2486.

[26] V. Ruiz, C. Blanco, R. Santamaría, J.M. Juárez-Galán, A. Sepúlveda-Escribano, F. Rodríguez-Reinoso, Microporous Mesoporous Mater. 110 (2008) 431.

[27] T. Momma, X. Liu, T. Osaka, Y. Ushio, Y. Sawada, J. Power Sources 60 (1996) 249.

[28] Y. Shao, G. Yin, J. Zhang, Y. Gao, Electrochim. Acta 51 (2006) 5853.

[29] V. Ruiz, C. Blanco, M. Granda, R. Santamaría, Electrochim. Acta 54 (2008) 305.

[30] E. Frackowiak, J. Braz. Chem. Soc.17 (6) São Paulo Sept./Oct. 2006

[31] A. Rolla, A. Sadkowski, J. Wild and P. Zóltowski, J. Power Sources 5 (1980) 189.

[32] K. Horita, Y. Nishibori, and T. Oshima, Carbon 34 (1996) 217.

[33] J. Koresh and A. Soffer, J. Electrochem. Soc. 124 (1977) 1379. 
[34] M. Nakahara, K. Shimizu, J. Mater. Sci. 27(1992) 1207.

[35] N. L. Weinberg, T. B. Reddy, J. Appl. Electrochem. 3 (1973) 73.

[36] Z.R. Yue, W. Jiang, L. Wang, S.D. Gardner, C.U. Pittman Jr., Carbon 37 (1999) 1785. 


\section{TABLES}

Table 1.- Specific capacitance values with the number of cycles performed at 0.6 and $1 \mathrm{~V}$. Current load $500 \mathrm{~mA} \mathrm{~g}^{-1}$.

Table 2.- Working potential values for positive and negative electrodes in $\mathrm{H}_{2} \mathrm{SO}_{4}$ and $\mathrm{KOH}$. 
Table 1.-

\begin{tabular}{lcc} 
& \multicolumn{2}{c}{$\mathbf{C}\left(\mathbf{F ~ g ~}^{-\mathbf{1}}\right)$} \\
\hline sample & $\mathbf{1}^{\text {st }}$ cycle & $\mathbf{7 , 0 0 0}^{\text {th }}$ cycle \\
\hline $\mathbf{H}_{2} \mathbf{S O}_{4} \mathbf{- 0 . 6 ~ V}$ & 194 & 178 \\
\hline $\mathbf{H}_{2} \mathbf{S O}_{4}-\mathbf{1 ~ V}$ & 242 & 204 \\
\hline KOH-0.6 V & 214 & 60
\end{tabular}

Table 2.-

V vs. NHE

\begin{tabular}{|c|c|c|c|c|c|}
\hline & Initial state & Vmax $_{+}$ & Vmax. & $\Delta \mathbf{V}_{+}$ & $\Delta \mathbf{V}_{\text {. }}$ \\
\hline $\mathrm{H}_{2} \mathrm{SO}_{4}-1^{\text {st }}$ cycle & 0,48 & 0,77 & 0,18 & 0,29 & 0,30 \\
\hline KOH-1 ${ }^{\text {st }}$ cycle & $-0,31$ & 0,04 & $-0,53$ & 0,35 & 0,22 \\
\hline KOH-a & $-0,15$ & 0,35 & $-0,22$ & 0,50 & 0,07 \\
\hline
\end{tabular}




\section{FIGURES}

Figure 1.- Variation in the specific capacitance values with current density obtained in $1 \mathrm{M}$ $\mathrm{H}_{2} \mathrm{SO}_{4}, 6 \mathrm{M} \mathrm{KOH}$ and $1 \mathrm{M} \mathrm{LiCl}$. Operating voltage $0.6 \mathrm{~V}$.

Figure 2.- Cyclic voltammograms in a three-electrode cell performed in: a) $\mathrm{H}_{2} \mathrm{SO}_{4}$, b) $\mathrm{KOH}$ and c) $\mathrm{LiCl}$ at a scan rate of $2 \mathrm{mV} \mathrm{s}^{-1}$.

Figure 3.- Variation in the specific capacitance values with the number of cycles obtained for $\mathrm{H}_{2} \mathrm{SO}_{4}$ (at 0.6 and $1 \mathrm{~V}$ ) and for $\mathrm{KOH}$ at $0.6 \mathrm{~V}$. Current load $500 \mathrm{~mA} \mathrm{~g}^{-1}$.

Figure 4.- Effect of cyclability performed for M-AC in basic media: a) cyclic voltammograms at $1 \mathrm{mV} \mathrm{s}^{-1}$ b) galvanostatic cycles at $500 \mathrm{~mA} \mathrm{~g}^{-1}$, c) Nyquist plots and d) high frequency region of the Nyquist plots and e) high frequency region of the Nyquist plots for M-AC in $\mathrm{H}_{2} \mathrm{SO}_{4}$

Figure 5.- a) Galvanostatic cycle for $\mathrm{M}-\mathrm{AC}$ in $\mathrm{H}_{2} \mathrm{SO}_{4}$ at $0.6 \mathrm{~V}$ (right $\mathrm{Y}$-axis) and the potentials of work for the positive and negative electrodes (dash-line in left Y-axis). b) Galvanostatic cycle for $\mathrm{M}-\mathrm{AC}$ in $\mathrm{KOH}$ at $0.6 \mathrm{~V}$ (right Y-axis) and potentials of work for the positive and negative electrodes (left $\mathrm{Y}$-axis) before and after the long-term cycling. (a.u.= arbitrary units). Current load $100 \mathrm{~mA} \mathrm{~g}^{-1}$.

Figure 6.- TPD profiles for the electro-oxidation of activated carbon. a) $\mathrm{CO}$ and b) $\mathrm{CO}_{2}$ evolution curves. 
Figure 1

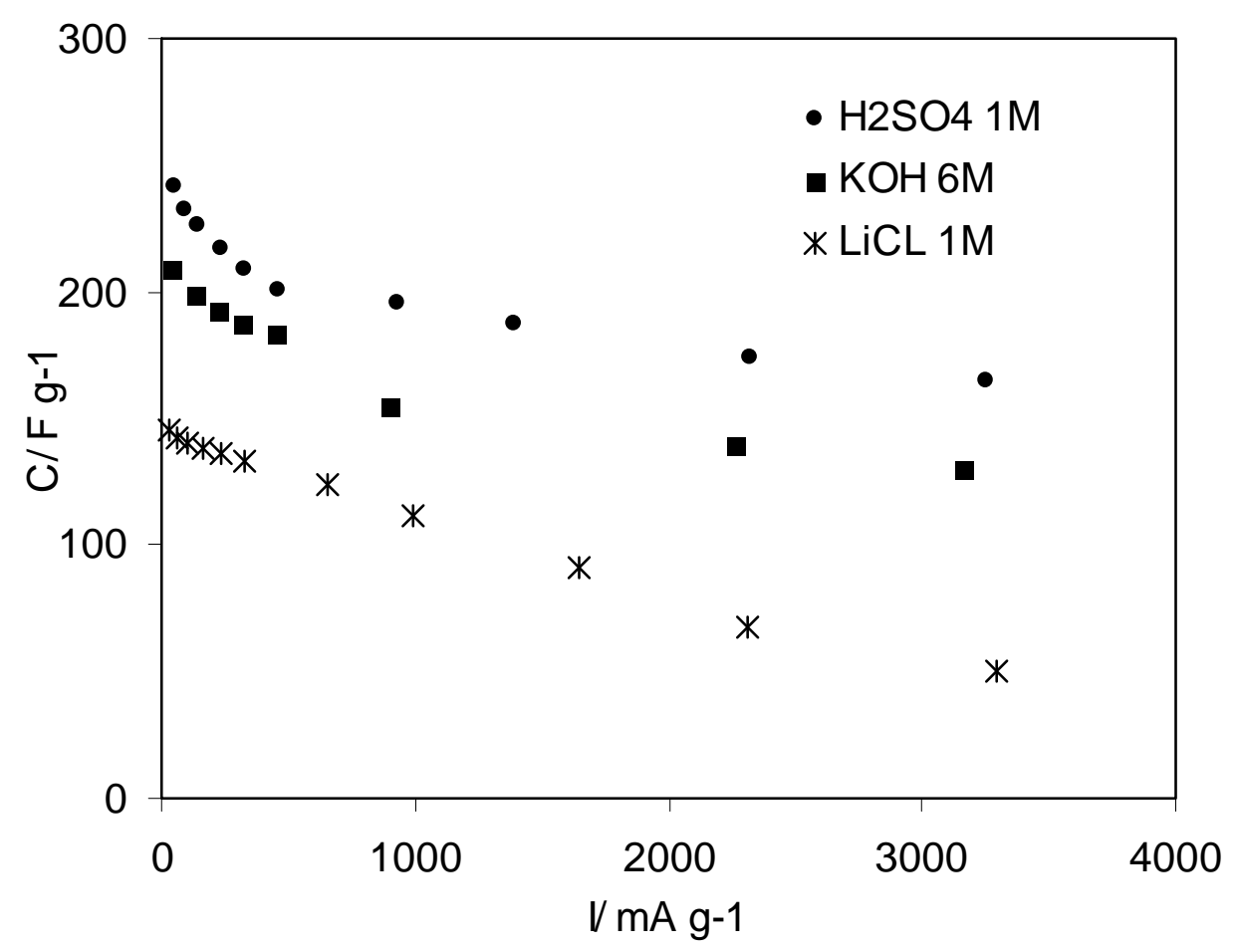




\section{Figure 2}

a)

b)
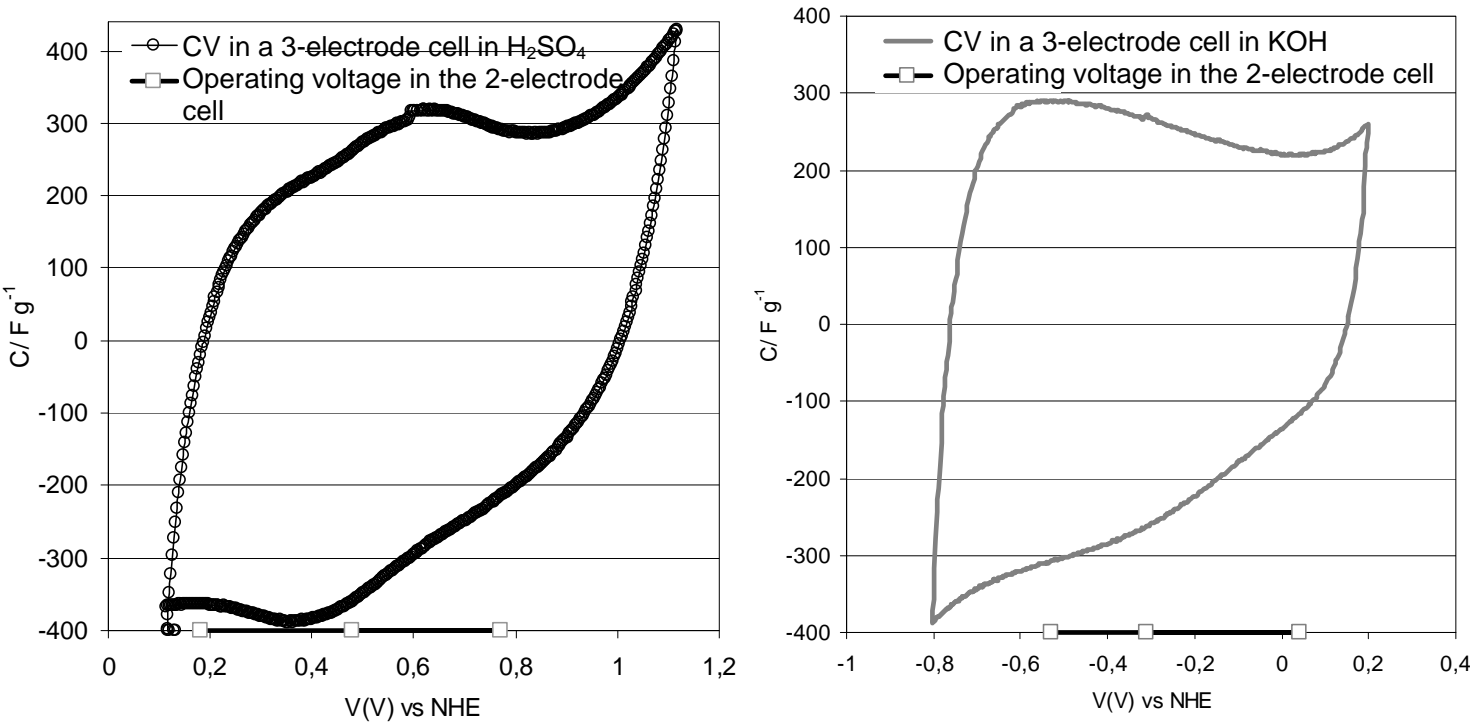
Figure 3

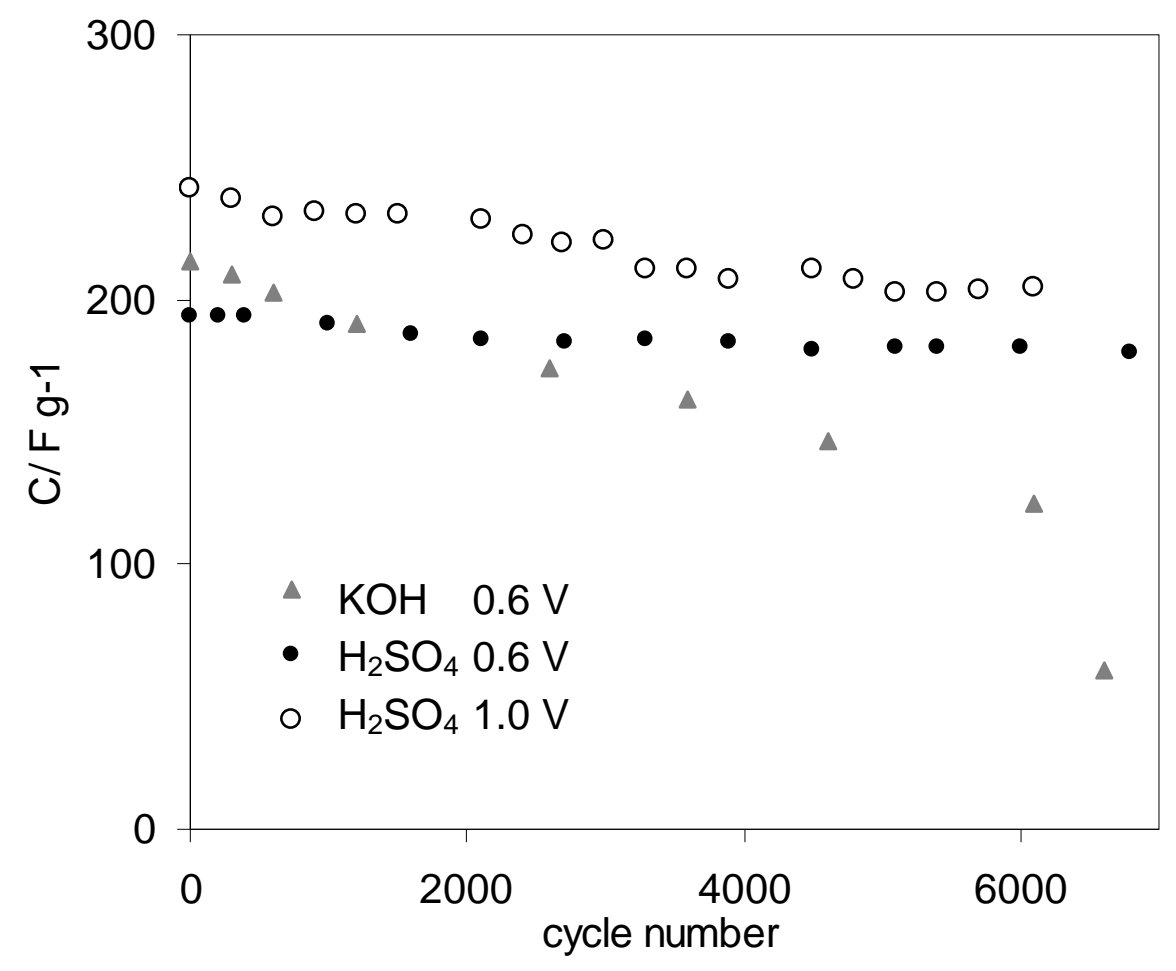


Figure 4

a)

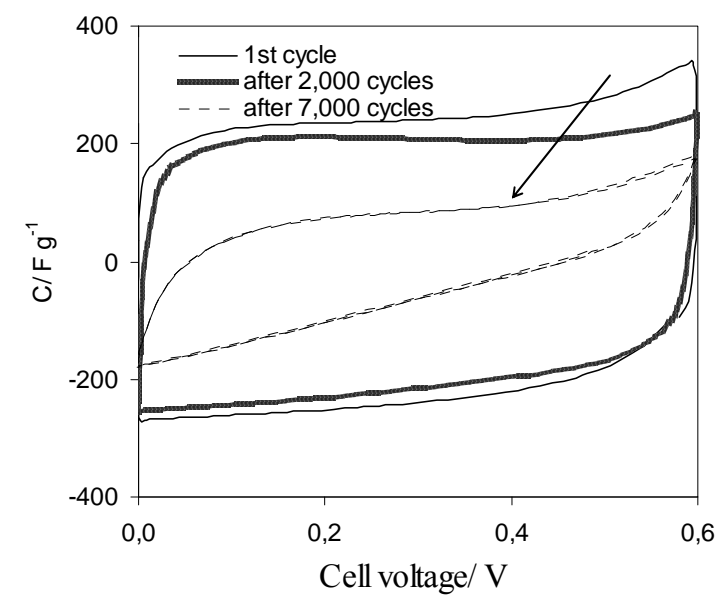

c)

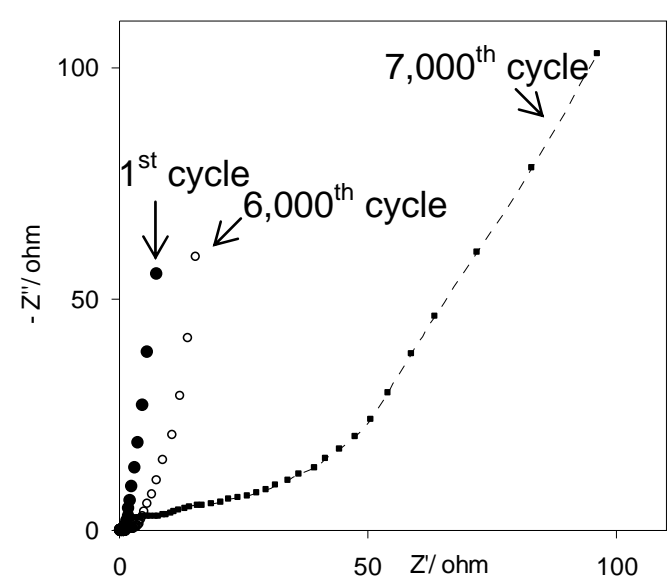

e)

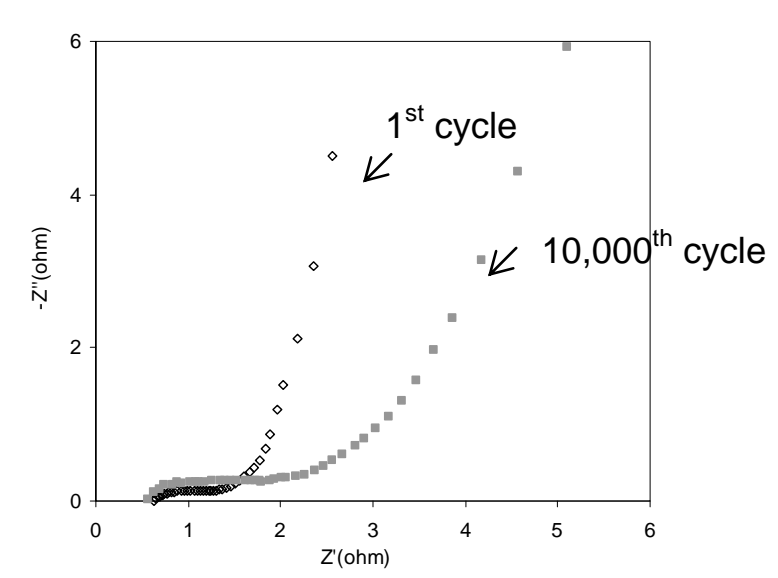

e) b)

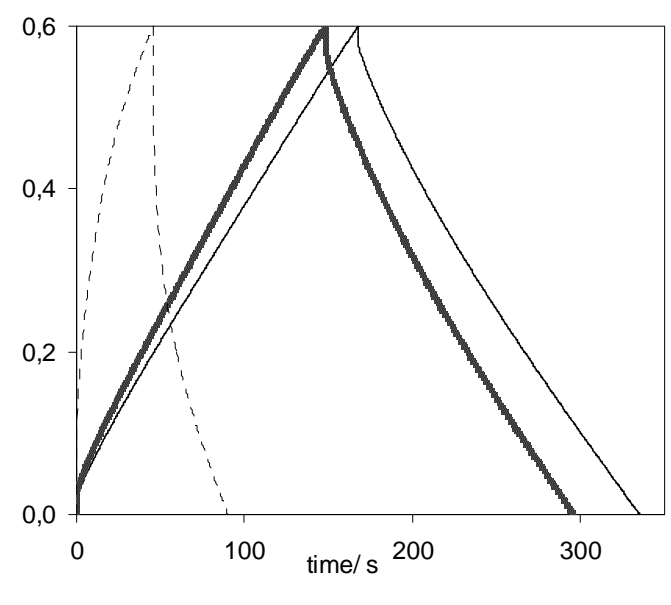

d)

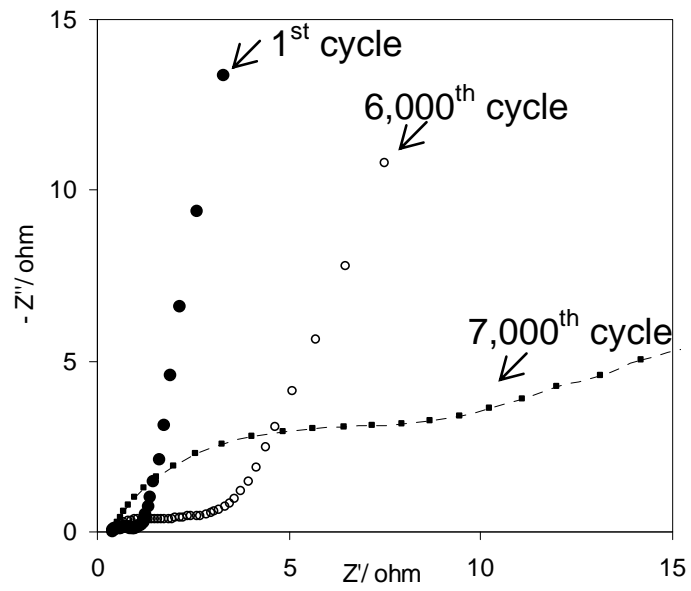


Figure 5

a)

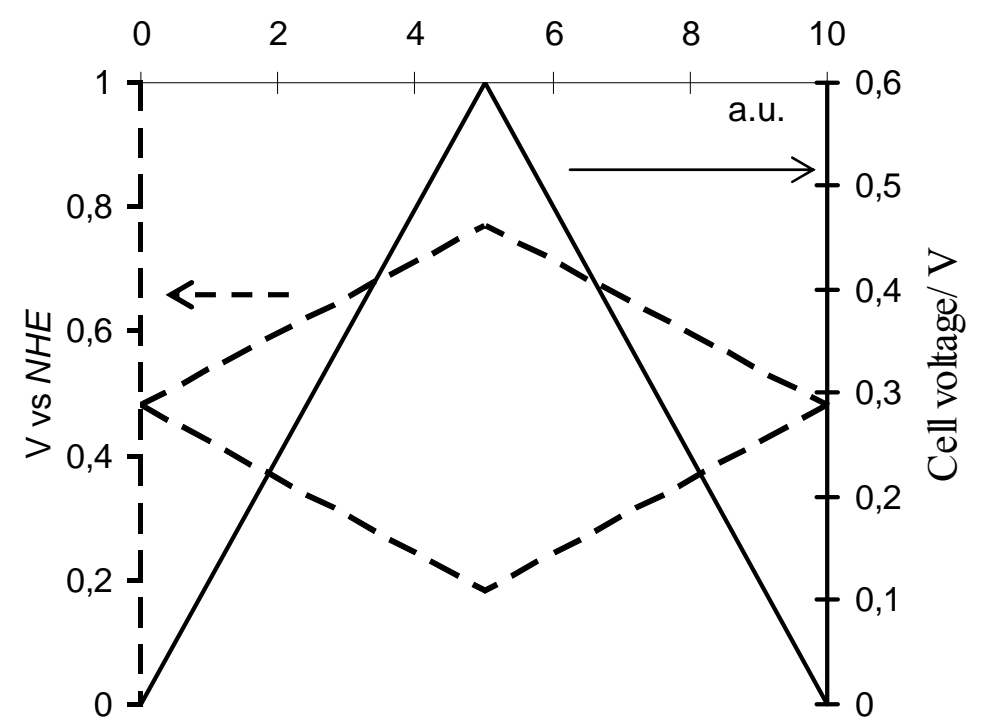

b)

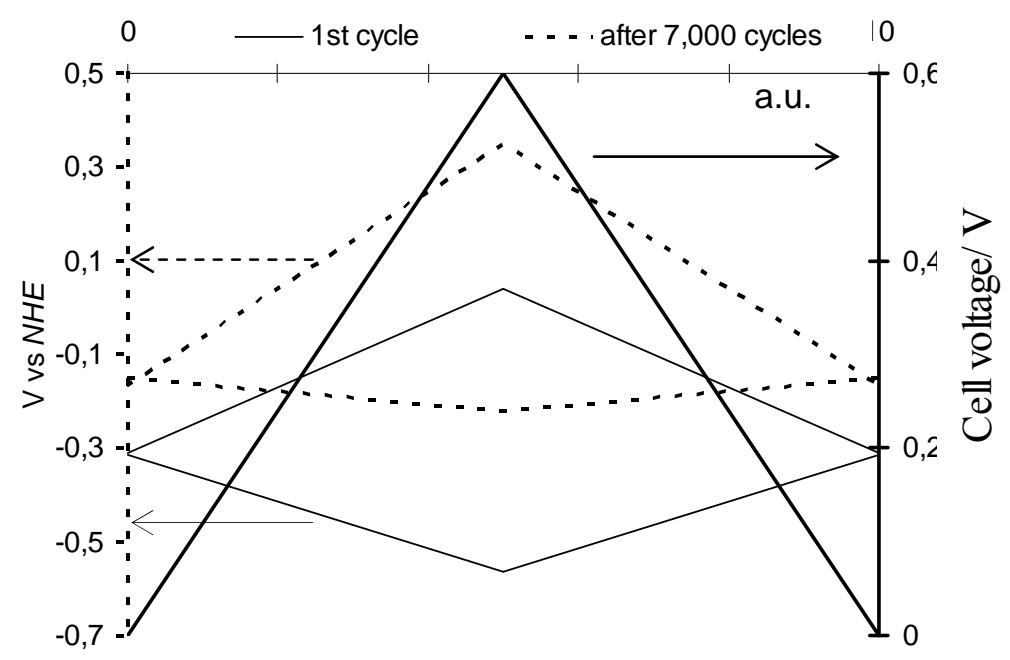


Figure 6

a)

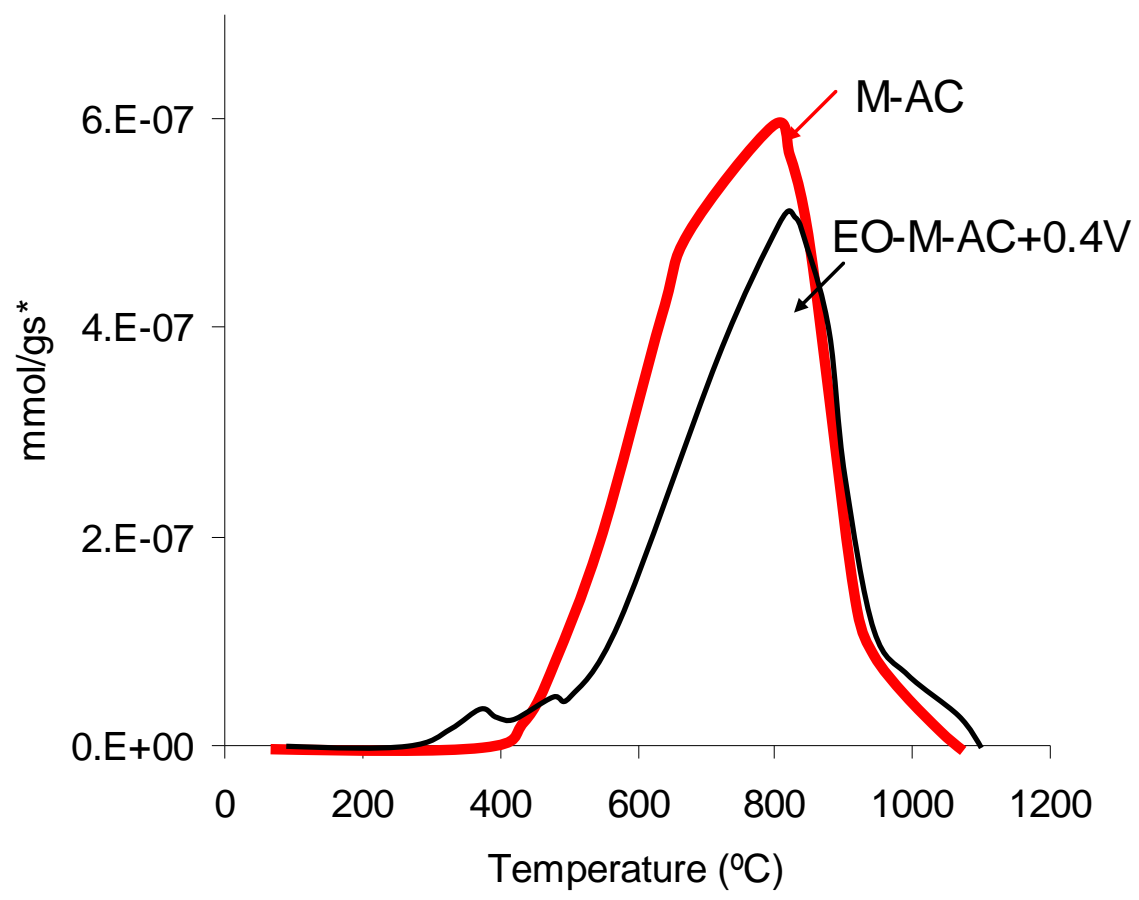

b)

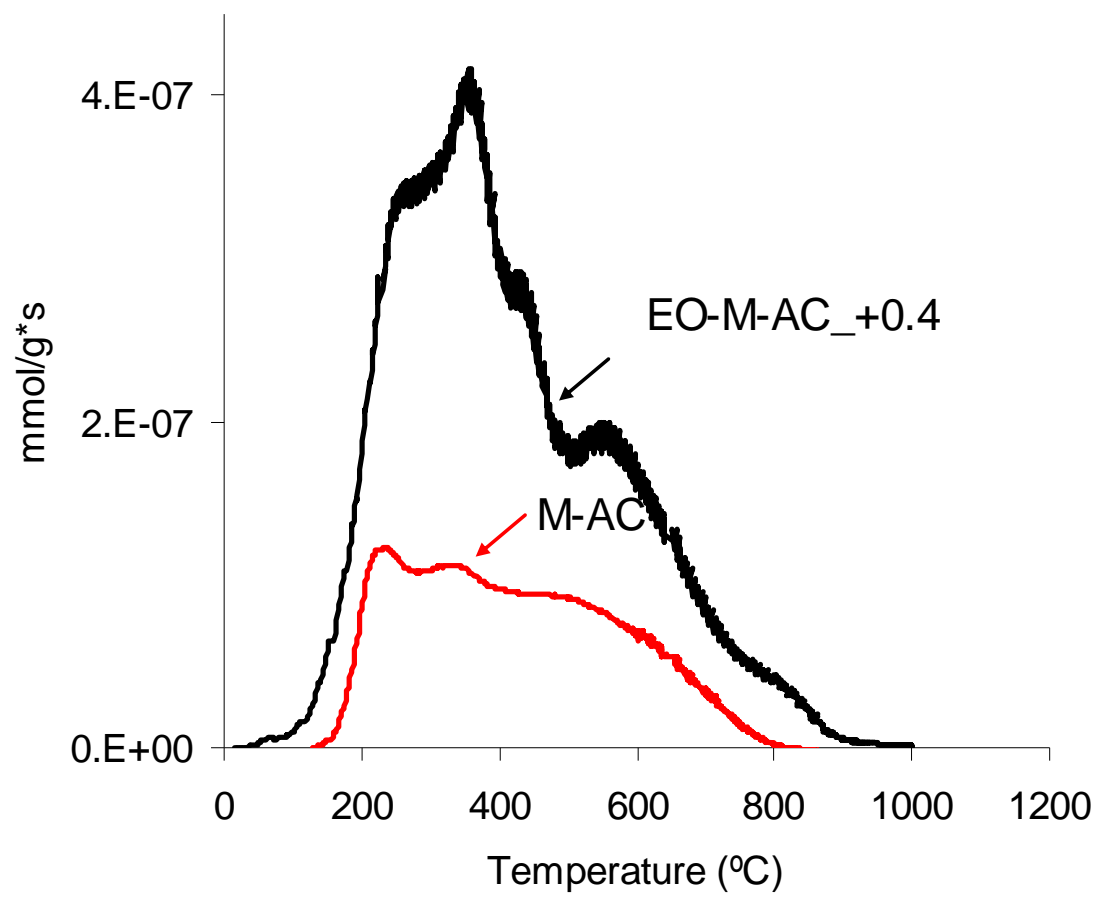

